\title{
Understanding and managing surface subsidence at New Gold's New Afton block cave operation
}

\author{
AGL Davies New Gold Inc., Canada \\ DB Hamilton New Gold Inc., Canada \\ MA Clayton BGC Engineering Inc., Canada
}

\begin{abstract}
New Gold's New Afton Mine is a 6 million tonne per year operating mine located $8 \mathrm{~km}$ outside of Kamloops, British Columbia, Canada. After $\sim 17,700 \mathrm{~m}$ of decline access, underground ancillary and footprint development, the first drawbell was blasted in September 2011. The ore being mined is a copper-gold porphyry deposit situated within the Iron Mask batholith complex, bounded by two major sub-vertical fault structures, and plunges to the southwest.

Determining the key components and driving mechanisms of surface subsidence is vital when considering potential impact on critical surface infrastructure. This paper will examine a number of fundamental learnings, starting from the initial feasibility study design assumptions through to actual cave behaviour and observed surface subsidence. As is the case in most start-up operations, early numerical modelling studies and inputs are often data poor and multiple assumptions need to be made. Furthermore, continuous and accurate calibration is required as subsidence evolves over time. This can be achieved through a better understanding of the regional geological model, and use of surface, subsurface and deep-seated instrumentation methods. At New Afton, we embarked upon an intensive instrumentation and drilling program to better understand the regional geological model and rock mass behaviour mechanisms, and their associated subsidence impacts.
\end{abstract}

Keywords: block caving, subsidence, numerical modelling, instrumentation

\section{Introduction}

The New Afton block caving operation at its current size is one of the smallest producing caving operations in the world. The current extraction level is located $615 \mathrm{~m}$ below surface and the current mining footprint is approximately $800 \mathrm{~m}$ long by $120 \mathrm{~m}$ wide. An El Teniente style footprint of straight-through drawpoint drives was selected as the optimum design due to various geotechnical and operational considerations.

The operation completed its first drawbell in September 2011 after $17,700 \mathrm{~m}$ of decline access development. Employing an advanced undercut method, coupled with an aggressive drawbell development and construction schedule, evidence from the apex level observations suggested that steady-state caving was achieved around April/May 2012. Cave breakthrough to surface occurred later that year in December 2012 with the first measurable and confirmed surface subsidence being recorded in a January 2013 drone flyover analysis. This breakthrough timing was also further confirmed by seismic back-analysis.

A large portion of the block cave is located beneath the historic Afton open pit (Figure 1), previously owned and operated by Afton Operating Corporation. Since millions of tonnes were relocated from the pit during stripping and push back operations, the ground surface has taken on a very different and artificial surface topography from the pre-mining state, with overburden depths attaining $110 \mathrm{~m}$ in some areas. The relevance of the earlier open pit workings is an important aspect regarding the observed surface subsidence behaviours at the New Afton site. The challenges and learnings from this fairly diverse and unique situation of highly variable overburden depths will be a key consideration as we step through the various sections in this paper. 
The principal driver in the quest to establish an improved understanding of the subsidence mechanisms and accurate progression predictions lay solely with the protection and preservation of critical surface infrastructure. The two tailings storage facilities (TSFs) are seen in Figure 1. The historic and inactive Afton TSF and the active New Afton TSF were obviously key impoundment structures that required protection from possible subsidence impacts. Another important operational concern was potential-cave related deformation impacts on the main vent raises.

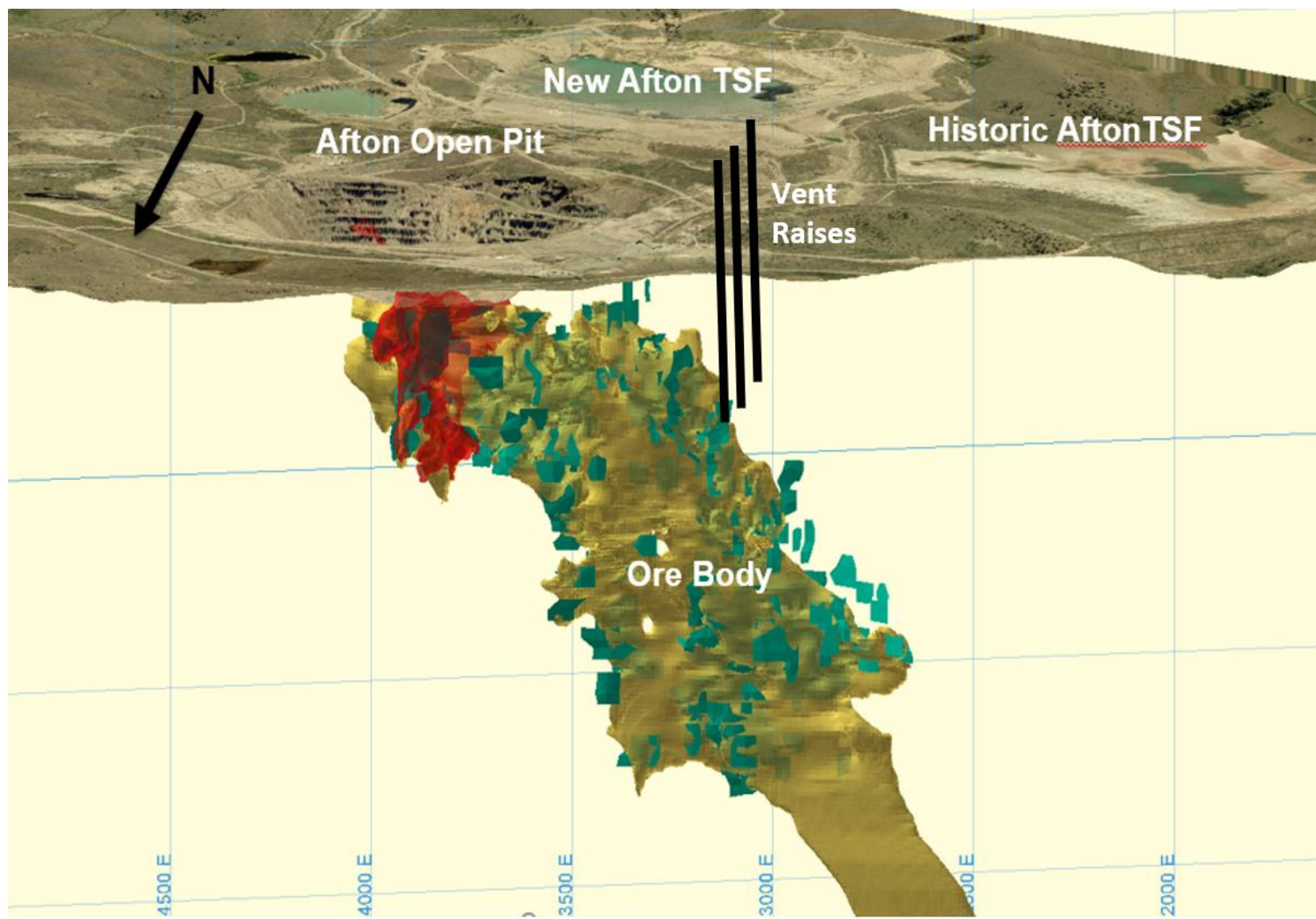

Figure 1 Isometric view (looking south) showing the general site arrangement of the historic Afton open pit, vent raises, the tailings storage facilities and the orebody plunging to the west beneath the open pit

This paper will focus on three main themes: (i) evolution, outcomes and the associated predictions based on the multiple and varied numerical models and techniques, (ii) instrumentation program implemented and the important geological findings and subsequent changes in the site regional geology, and (iii) subsidence mechanisms as interpreted from the instrumentation data based on the surface and subsurface rock mass behaviour.

\section{$2 \quad$ Geologic setting}

New Afton is located in a belt of 200-205 Ma alkali porphyry Cu-Au-Ag deposits situated in the Quesnel volcanic arc. The deposit is classified as an alkalic porphyry copper-gold deposit related to the intrusion of a narrow monzonite stock that is associated with the Cherry Creek monzonite phase of the Iron Mask batholith (Lipske \& Wade 2014). Mineralisation occurs as discontinuous copper sulphide stringer veinlets and disseminations hosted in intermediate to mafic volcanic rocks belonging to the Triassic Nicola Formation immediately adjacent to monzonite intrusions. 


\subsection{Lithology}

The New Afton lithological model is comprised of six principal units - crystalline and polymictic fragmental volcanic rocks and monomictic intrusive breccias (BXF), picrite, diorite, monzonite, sedimentary rocks and major faults including the Hanging Wall Fault (HW Fault) and Footwall Fault (FW Fault).

The principal host rock comprises crystalline and polymictic fragmental volcanics belonging to the Triassic Nicola Formation and lesser monolithic intrusive breccias consolidated into one lithology informally referred to as 'BXF'. On the eastern half of the deposit, BXF is intruded by a coeval diorite sill. A rheological discontinuity occurs through the central and western parts of the deposit between an ultramafic flow (picrite) and brittle volcanic rocks. An elongated monzonite stock and dyke swarm intrudes the BXF and is controlled by the HW Fault and picrite along the southern margin of the deposit. The monzonite is generally weakly mineralised to mineralised and its geometry is best described as a narrow elongated stock that remains open at depth and pinches down plunging to the west.

Of interest and believed to be an important role player, is the picrite unit and its generally poor rock mass rating; the unit is south of the extraction footprint, and highly serpentinised and sheared along fault contacts. Drilling through the picrite has proven to be nearly impossible, but samples recovered from drawpoints confirm that the unit exhibits increasing competency south of the HW Fault and distal to other localised structures.

\subsection{Structure}

Four major structural trends have been recognised. The earliest and most prominent structures are near-vertical east-trending faults referred to as the FW Fault and HW Fault. The structural corridor formed by the HW Fault and FW Fault likely controlled the emplacement of the monzonite and created a narrow space environment for the concentration of gold and copper mineralisation. The HW Fault is defined by carbonate healed faults along the picrite-BXF contact including rubble zones near carbonate-healed faults; the fault zone includes blocks of BXF, picrite, diorite and monzonite.

\section{$3 \quad$ Numerical modelling}

The earliest available modelling providing the first set of results for subsidence predictions was back in 2007 and formed part of the original caving feasibility study. Now, 11 years later after the first model and six years since production commenced, New Afton has seen numerous model runs, calibration efforts and updated subsidence predictions.

The two numerical modelling methods used during this 11 year period, and referred to in the next few sections, each have their own unique caving algorithms, means of simulating cave draw, growth and, ultimately, subsidence solutions.

The intent of this paper is not to pit one numerical model type or consultancy against the other, since both modelling methodologies provided very good predictive outputs at various phases throughout the cave progression. However, it would be valuable for the readers to get a brief overview of the processes used within each model.

For the Itasca model, which uses a caving algorithm developed within the concept of a continuum-based model, the constitutive rock mass response required to represent caving (i.e. rock mass yield, weakening, dilation and bulking) was developed using strain-softening material models, with strain-dependent properties adjusted to reflect the impacts of dilation and bulking that accompany caving. This method was used exclusively during the first three to four years of caving at New Afton and very good calibration and predictive results were achieved.

Later on, around mid-2015 a further development occurred, in which the model was reconfigured to better account for mass balance and simulation of the airgap and caving mechanics (Sainsbury et al. 2008). This new caving algorithm was introduced together with a particle flow code to simulate the softer overburden 
materials. However, as discussed later in this section, the variance between actual subsidence (i.e magnitude and extent) versus the model predictions simply became too large in the Itasca model to satisfy our needs and risk tolerance.

In 2016, we decided to employ a different modelling approach and engaged with another modelling specialist, Beck Engineering.

A fully coupled model (Beck \& Putzar 2011; Beck et al. 2011; Levkovitch et al. 2010), using a Newtonian cellular automata (NCA) method to simulate cave draw and flow, and a strain-softening dilatant discontinuum (SSDD), combined with a hydromechanical (HM) component (Flatten et al. 2015) was used.

In this type of three-way coupled analysis, physics-based analysis of cave flow (NCA), the strain-softening, dilatant discontinuum (DFE) and HM parts are solved together, exchanging data at selected intervals (monthly to quarterly in this case) for the cave draw-deformation coupling and in parallel for deformation and water flow/pressure.

This model proved highly successful, and after several iterations and model calibration steps, very good calibrated results were obtained. The subsidence predictions to date have also been tracking extremely well with all our field data.

\subsection{Pre-mining subsidence modelling}

A couple of early subsidence model runs and internal reports (Gibson 2008) could be traced back to 2006 through to 2009. One of which was used in the original feasibility study of 2007 (Thomas \& Stewart 2007).

\subsubsection{Structural inputs and early models}

Extracted from these earlier modelling reports are contour plots of vertical displacement (Figure 2). These plots also represent outputs from different numerical methods and were conducted and compiled by different numerical modelling specialists. The dark lines in Figure 2 represent the main geological structures that were interpreted from the exploration drilling at the time and consequently used as geotechnical inputs in the two numerical models. The contours and associated values are deliberately not shown in Figure 2, as different ranges were used in the models. This is, however, significant and hence discussed later in this section.
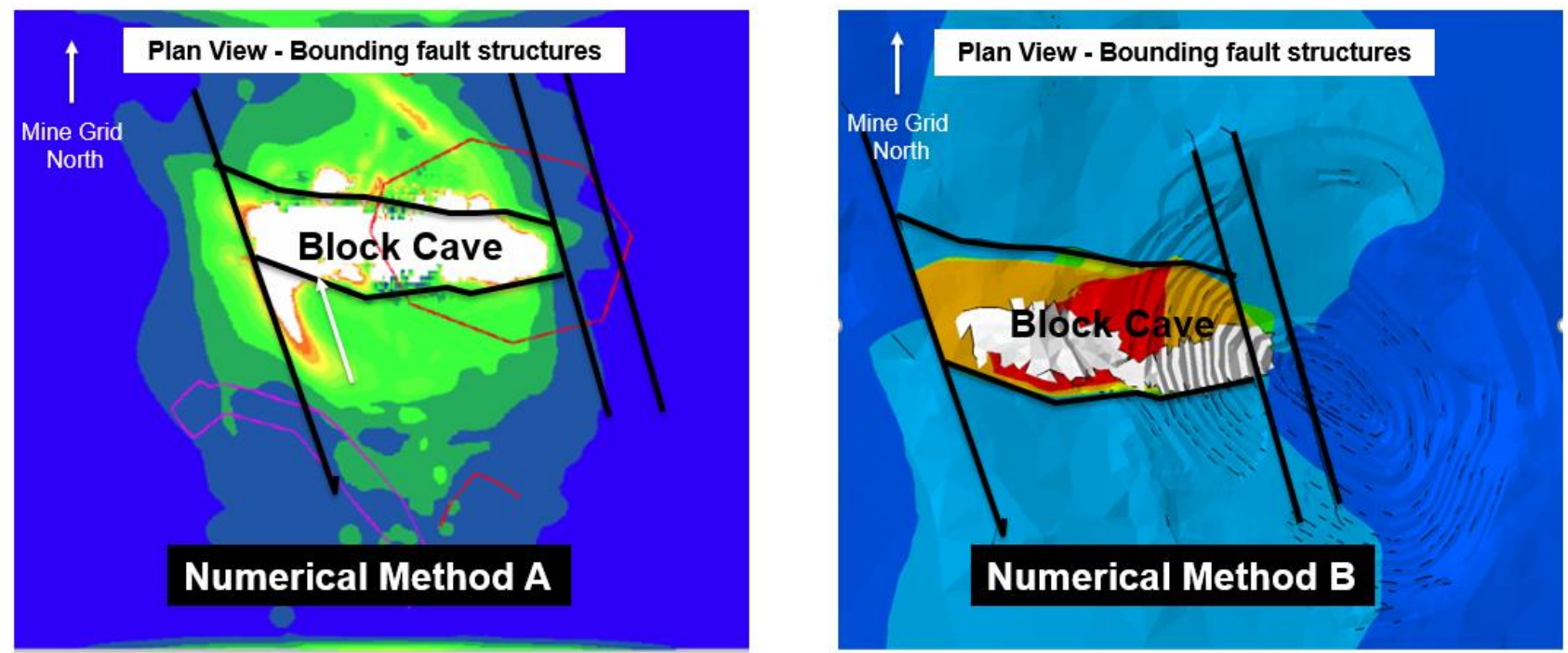

Figure 2 Plan view showing vertical displacement contour plots in conjunction with the early structural representation (black lines) bounding the deposit 
Figure 3 is a representation in section view of the same geological model used in the simulations above, showing the relative scale of the orebody and the earlier interpreted dominance of the bounding HW Fault and FW Fault zone structures at the time.

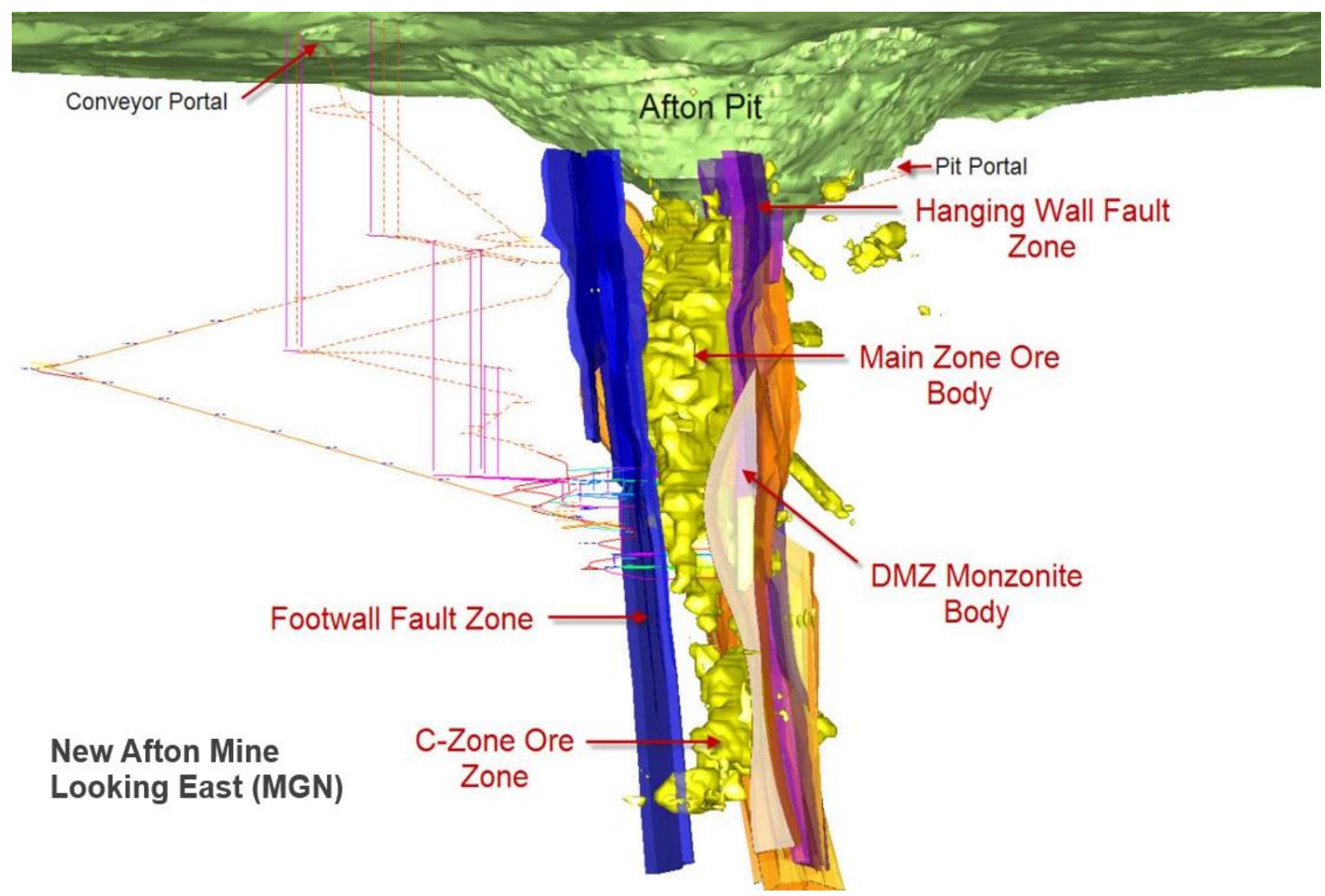

Figure 3 Section view (looking east) of deposit showing the relative location of the HW Fault and FW Fault zones

\subsubsection{Pre-mining subsidence predictions}

One of the key observations evident from the early modelling is the similarity in how both models allowed the major fault structures to dominate the subsidence behaviour. As referenced earlier, although not shown in the vertical displacement contour plots (Figure 2), the magnitude of the predicted subsidence between the bounding structures, particularly the HW and FW Fault zones, was in the order of several metres (>10 m). In contrast to this highly mobilised zone located between the faults, the subsidence profile outside of those bounding structures had a range of a few centimetres $(5-15 \mathrm{~cm})$, which would be indicative of typical elastic behaviour.

There was also a strong case made in some of the early reports that the existence of these major structures bounding the deposit would not only be hugely beneficial in cave propagation, but they would also effectively confine the surface expression of the cave to a much smaller area. Both models seemed to support that theory in their respective outputs.

\subsection{Production (caving) phase modelling}

Since 2012, soon after New Afton went into commercial production and rapid drawbell development and construction was taking place, annual and, in some cases, semi-annual subsidence models and internal reports have been generated. The strong emphasis of calibration to our flyover analyses is rooted in all models. Naturally, refined and improved geotechnical domaining was incorporated with each successive model as more information was gained on rock mass properties, structural persistence and lithological boundaries. 


\subsubsection{Cave breakthrough and first calibration efforts}

With breakthrough occurring in January 2013, it provided us with the first important dataset on the initial cave behaviour. From this early information on the subsidence profile, it was soon apparent that the breakthrough 'crater' location (in the absence of well-defined shear surfaces, we have defined this as the central and lowermost portion of the subsidence bowl) was offset approximately $150 \mathrm{~m}$ southwest of the centre of the cave footprint (Figure 4).

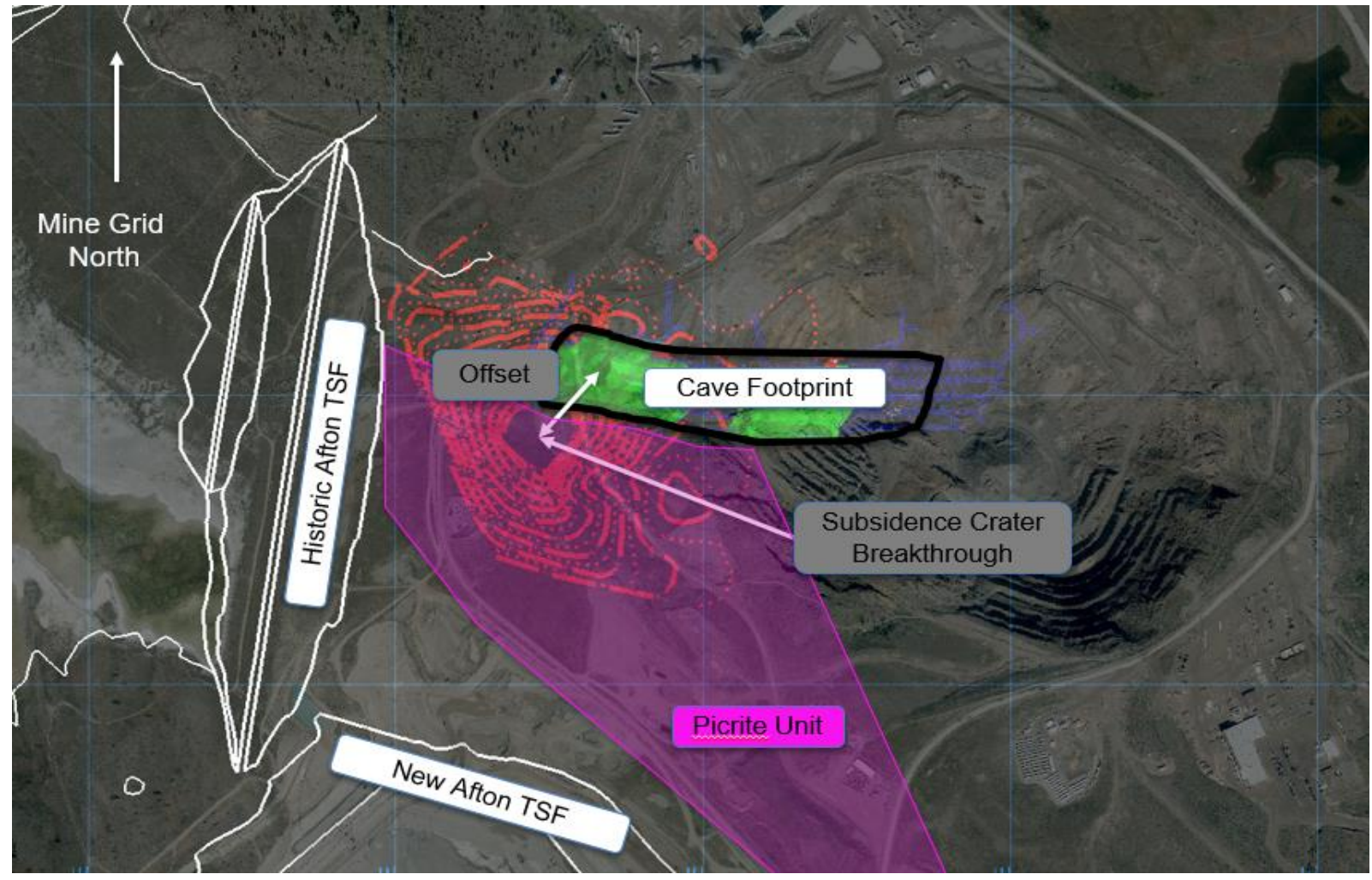

Figure 4 Plan view showing the subsidence offset location relative to the cave footprint and the position of the picrite unit

With the new field information on-hand and the ability to generate true subsidence profiles from the flyover analyses, the next few model iterations were developed to effectively try to replicate the observed asymmetrical subsidence profile. As part of the calibration attempts, in an effort to understand the reasons for the crater offset location from the west cave, the role potentially played by the extensive picrite unit lying immediately adjacent to the HW Fault was closely scrutinised. This unit exhibited highly incompetent characteristics with typical values of $<25 \%$ rock quality designation (RQD). This unit had been identified as a distinctly different geotechnical domain and was incorporated as such in the numerical models, but it was thought that provided the cave propagated vertically, any cave exposure into this unit would be shielded by the neighbouring HW Fault.

After several adjustments to rock mass properties, particularly within the picrite lithology and including improved overburden and weathered zone inputs from drillhole data, reasonable success in calibration was achieved in the next few models over the following few years. The asymmetrical subsidence with bias to the south was maintained and a good match to reality was held through until around mid-2015.

\subsubsection{Later models and calibration}

A gradual increased deviation in observed behaviour to model predictions became apparent during mid to late 2015. The models used at that time simply continued to underestimate the subsidence extents and the magnitude of the subsidence. It was definitely concerning during that period as we had a sudden step-out and increase in our subsidence footprint and the growth was predominantly to the south and west towards 
the two TSFs. Although the $0.5 \mathrm{~m}$ subsidence contour was still a few hundred metres from the TSFs, there was an obvious need to re-establish a calibrated model state to provide us with improved confidence in our prediction estimates as related to our life-of-mine planning.

Even after conservatively adjusting parameters to check on sensitivities in terms of overburden moduli, friction angles, roughness coefficients, cave bulking factors and introducing a full particle flow code superimposed on the hard rock model codes, we still could not replicate the true behaviour seen on surface.

As mentioned earlier in this section, our next step was to change tack completely and contract another modelling specialist (Beck Engineering) to see if another numerical method would provide us with answers and, hopefully, improved calibration. This was a strategy that paid off almost immediately. Also, as a sensitivity in the new model, we asked that a hydro component be included.

In early 2017 we had a new calibrated model, and there have been two subsequent runs since then and we still appear to be in line with the initial subsidence predictions. It must be noted that the addition of a hydrogeological component did not have a very large effect on the overall behaviour within the model. The cave-induced mechanical component had, by far, the largest impact on the overall subsidence profile prediction. The hydro component influence seemed largely restricted to providing some small additional perimeter subsidence growth.

\subsection{Subsidence modelling learnings at New Afton}

Many caving operations are faced with a lack of data when pre-feasibility and feasibility studies are conducted, and many designs and assumptions are made with limited datasets. However, the learnings at New Afton on the actual subsidence behaviour versus some of the modelling predictions could add value to other operations where similarities may exist.

- The major bounding fault structures were large weak-faulted shear zones and they did not constrain or control cave propagation. Since these structures are not single-planar, well-defined discrete planes of weakness, they had no controlling influence on confining the cave and deposit to their relative spatial positioning.

- The picrite lithology unit, as expected, became a very dominant unit once it had been undercut or exposed. It is suspected that the cave propagation was near-vertical for the first part of its growth and then breached through the HW Fault and exposed the incompetent picrite unit, which in turn allowed preferential caving to the south.

- Evidence of episodic subsidence progression occurred at New Afton at a very mature state in the caving operation. Numerical models cannot predict this mechanism, so it is critical to conduct backanalyses through field observations on any formation of early scarp development and under what conditions and timing they occurred. This will provide information and assist subsidence 'step out' predictions.

- Modelling of the uncompacted overburden materials was a huge challenge at New Afton. This was primarily due to the extreme depths involved and the difficulty in assigning suitable properties to material that had been erratically placed by dump trucks during the original open pit operation.

- It is recommended that various modelling approaches or model types that employ different caving algorithms and solutions are considered early on in the caving process. Ideally, they should be ran in parallel to establish which of the models are providing a better fit to reality. Furthermore, predictive model output deviations from actual must be tracked carefully and reacted upon promptly.

- A robust surface and subsurface monitoring system is recommended to complement subsidence models. Data which can be used to refine models and ultimately validate spatial rock mass deformations, mechanisms of movement and rates thereof should be collected. 


\section{$4 \quad$ Instrumentation program and geological refinements}

In order to gain a proper understanding of the surface and subsurface rock mass behaviour and to get a better insight into the drivers of the actual mechanisms, an intensive instrumentation program, using a phased approach, commenced in 2011. There were a number of objectives identified in the program, but one of the primary considerations in conjunction with establishing a robust and informative monitoring network, was to improve our structural and lithological knowledge, particularly in the areas to the south and west of the deposit.

\subsection{Instrumentation program}

Only a very high-level summary is given here as the details of this large instrumentation program and monitoring network implemented over multiple phases over the past six years has been captured in a separate companion paper (Clayton et al. 2018) at this symposium.

The instrumentation program which commenced in the latter part of 2011 prior to any cave-related subsidence activity was an array of time domain reflectometry cables (TDRs) and microseismic sensors, and focused mainly on the monitoring of cave growth. The surface network consisted of a dedicated network of surface prisms. This monitoring network served the site for a number of years.

In 2014, several more phases of instrument installs were implemented throughout the site to specifically monitor subsidence and the associated rock mass behaviour. This network of instruments included slope inclinometers (SIs), one shape array accelerometer (SAA), TDRs, vertical- and horizontal-mounted multiple-point borehole extensometers (MPBXs), vibrating wire soil extensometers (VWSEs), pin-extensometers, additional survey prisms and an array of survey 'lock blocks' (concrete blocks with targets). Ground surveys of the extent of cracking, and drone-based photogrammetric surveys were also used to monitor the progression of subsidence.

The data obtained from this large surface and subsurface network of instrumentation has been fundamental in our understanding of the rock mass mechanisms and is discussed in the next section of this paper.

\subsection{Drilling results}

The majority of the drilling completed was beyond the scope of exploration work done to define the New Afton orebody; as such, this new drilling provided valuable insight into regional trends to the south of the Afton Pit.

\subsubsection{Structure update}

Many of the major structures modelled at depth had been projected along strike to give their relative positions to the south, resulting in through-going structures with very little relation to each other. Regional drilling allowed for the model to be refined, and for the definition of cross-cutting features to be developed. Though few new structures were identified, many previously modelled structures had their locations and orientations adjusted. Figure 5 shows the evolved structural model as at 2017, which was first developed in 2014 and lacked any definition drilling to the south. Figure 6 illustrates the newly modelled New Afton structures, and is a combined interpretation from the original structure model that incorporates all data from the entire instrumentation program. 


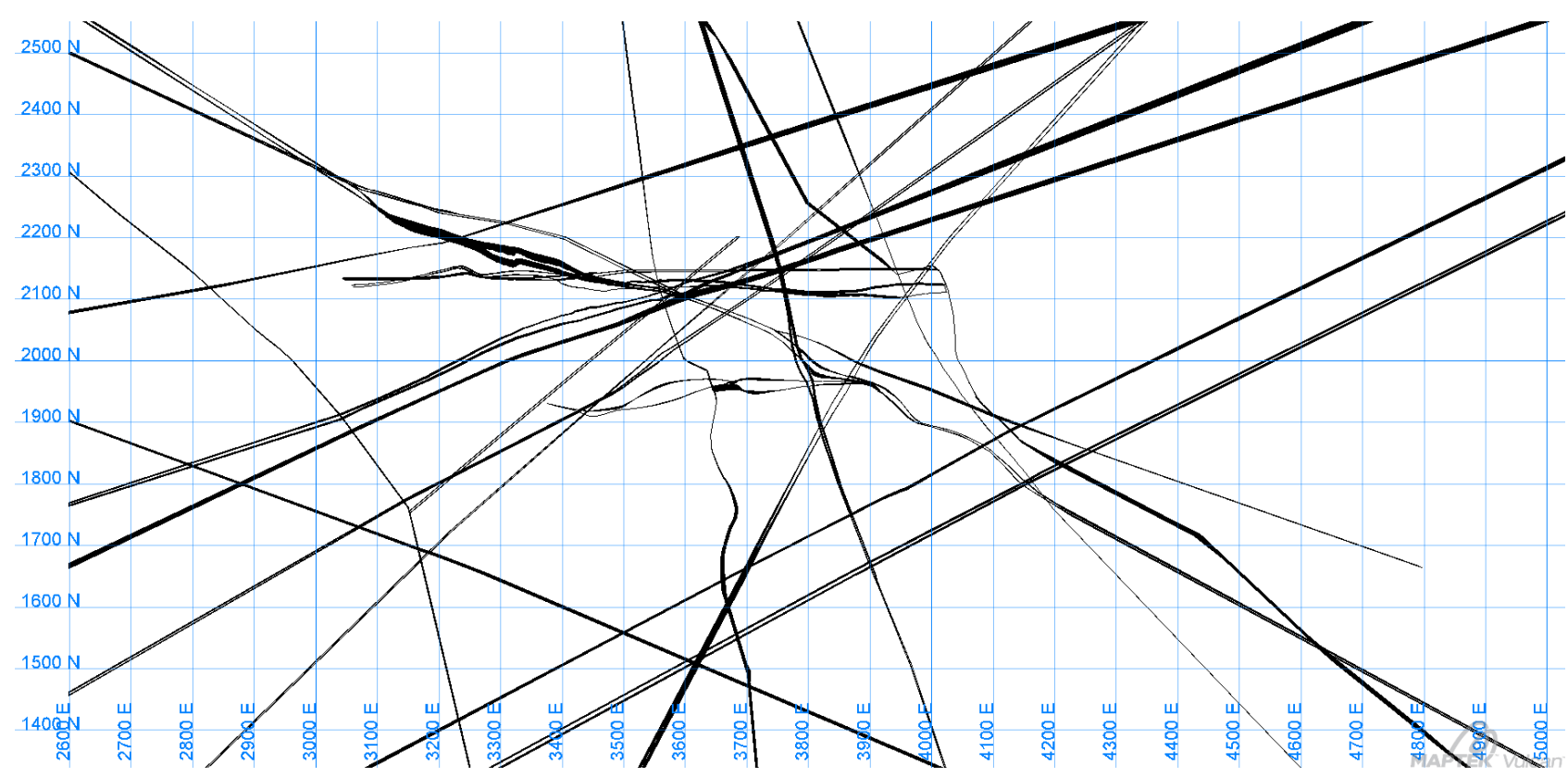

Figure 52017 New Afton structure model at the extraction level

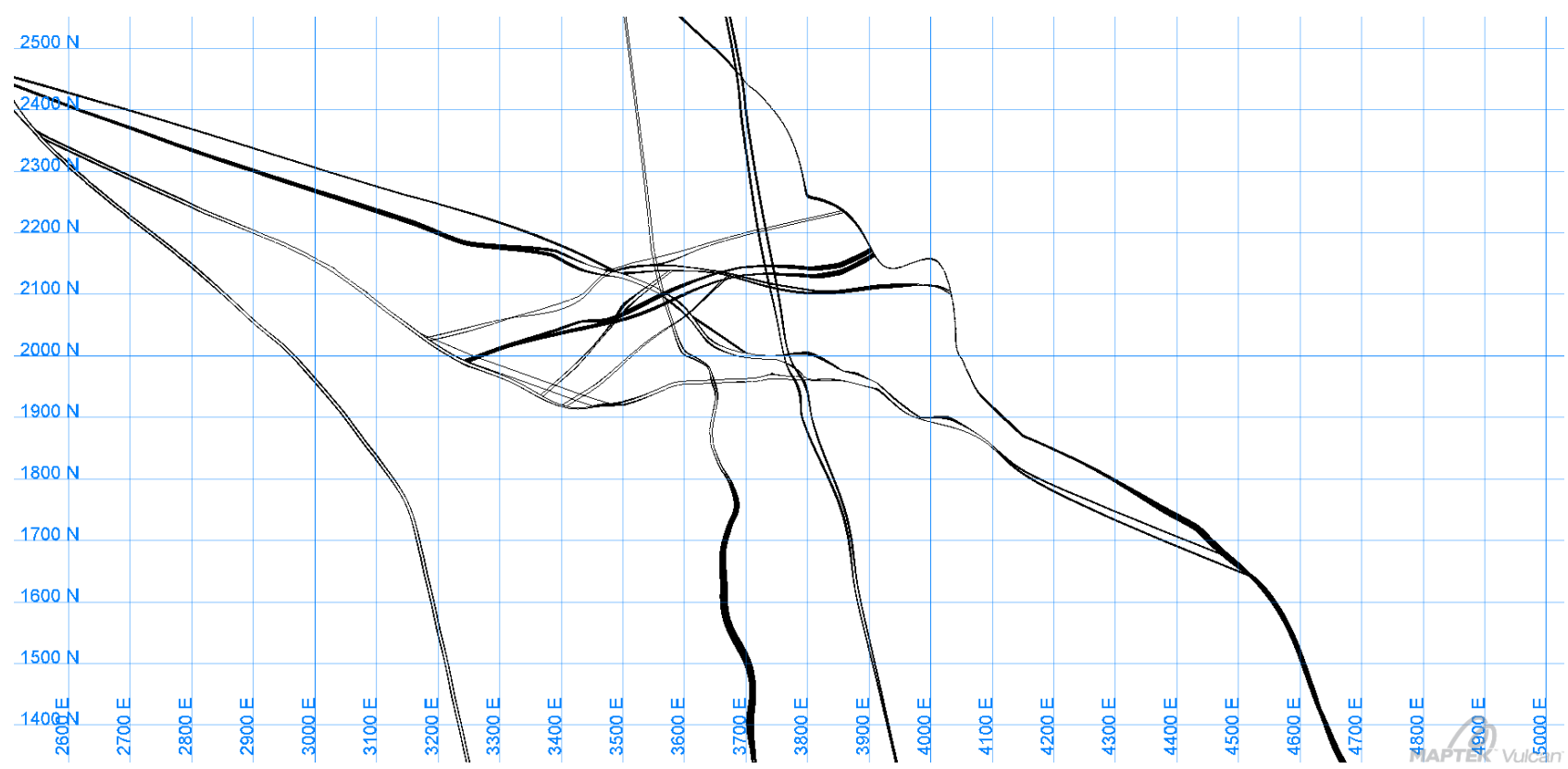

Figure 62018 New Afton structure model at the extraction level

\subsubsection{Lithology update}

Regionally, the lithology model around the New Afton mine had been well-developed by the exploration team, and drill results from the surface subsidence program provided assurance to contact locations, and allowed for minor adjustments to be made. Throughout the drill program, a continuous northwest-southeast trending trough of what was previously identified as Ashcroft Group conglomerate, was drilled through. This highly oxidised polymictic pebble conglomerate unit proved to be more extensive than previously modelled, both along strike and to depth, and has been emplaced along the Jurassic Ashcroft sediments and the Late Triassic Nicola Group picrite contact. The extent of the newly modelled polymictic conglomerate gives light to both the general permeability of the bedrock south of the pit and throughout the active subsidence zone, and the overall weak rock mass that makes up a good portion of the initial West Cave subsidence crater. 


\subsubsection{Overburden characteristics}

Overburden throughout the subsidence zone includes native glacial till and waste material that was placed during operation of the Afton Mine. Depths of overburden throughout the surface subsidence program ranged from 22 to $110 \mathrm{~m}$ and provided challenging installation conditions for both the vertical SI installations, as well as the inclined TDR installations. When taking into consideration the overburden depths above the newly defined conglomerate, the extent of poorly consolidated material within the subsidence zone increased significantly.

\section{Subsidence monitoring and deformation mechanism interpretation}

The extent of ground cracking has propagated progressively outwards from the crater breakthrough asymmetrically. The furthest cracks from the block cave footprint are found towards mine grid south, approximately perpendicular to the long axis of the cave and corresponding to the location of the weak picrite unit. Monitoring data collected from the New Afton instrumentation system, described in Section 4.1, was used to develop an understanding of deformation mechanisms controlling block cave-induced subsidence at New Afton.

\subsection{Surface cracking}

The surface cracking patterns and behaviour at New Afton vary spatially. The dashed line traces in Figure 7 , which depicts the total subsidence contour plot and the associated drone photogrammetry clips, clearly shows the observed linear and radial surface crack patterns. East and west of the block cave footprint, surface subsidence appears to be controlled by largely northeast-southwest trending structure. Ground observations of significant scarps with intact blocks behind and analysis of topographic survey data shows vertical ground displacement truncated against linear features that corresponds to mapped fault traces.

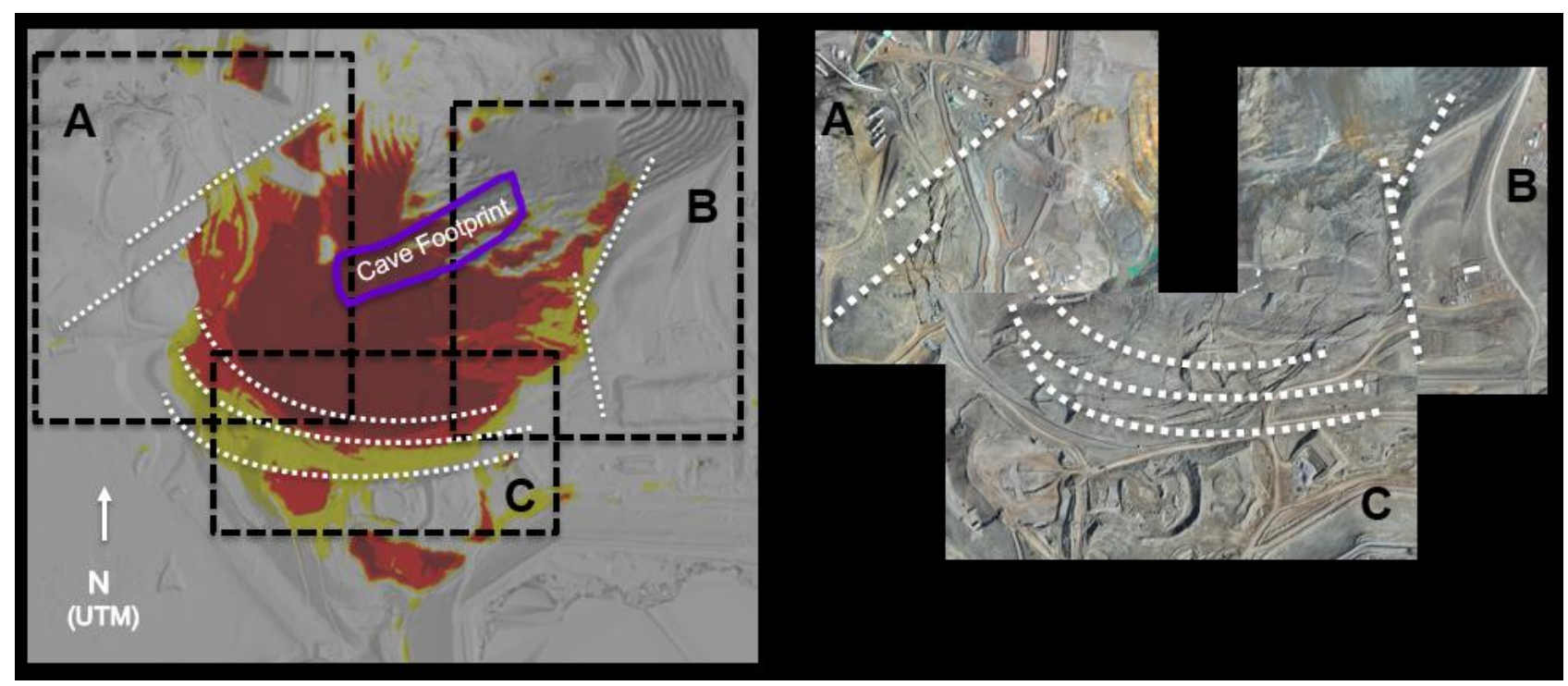

Figure 7 Plan view of total subsidence vertical displacement contours showing geometrical crack correlation (white dashed lines) patterns with the drone photogrammetry images 
South and southwest of the block cave, the tension cracks display an obvious radial fracture pattern and superficially suggest no evidence of any structural control. Displacement vectors near the southwest wall of the Afton Pit are towards the northeast, into the zone of decreased confinement created by the deepening crater and the Afton Pit wall. Bedrock structures within the pit wall are progressively dilating in response to the mining and crater deepening. Prisms adjacent to the pit wall show sequential initiation of bedrock movements in this area, with movement directed towards the northwest (towards the active mining and not the historical topping failure described in Reid \& Stewart 1986). Crack scarps in this area have developed along linear features which correlate with geologic structures, similar to behaviour observed east and west of the cave. Aerial photos show gradual southwest extension of these cracks, which have grown to connect with cracking observed south of the block cave and have been correlated with subsidence monitoring inclinometer data.

South and west of the block cave, there are substantial thicknesses of overburden material; both native glacial sediments and waste material placed during operation of the Afton Mine. Surface subsidence in this area manifests as large deformations (metres) with discrete deformations along significant crack scarps closer to cave (discontinuous zone), and gradual or continuous vertical and horizontal ground displacements (centimetres) farther away (continuous zone). Ground cracks found in the waste rock deposits can be divided into several categories based on their behaviour - those that have experienced rapid growth and appear to be connected directly to underlying bedrock movements, those which experience slower growth and continuous deformation behaviour, and hairline cracks which represent the advancing front of larger deformations. The latter two are interpreted to be responding to stress relief and extension of the thick overburden towards the crater.

\subsection{Monitoring data interpretation}

Monitoring and structural data collected from 2015 to 2017 has been used to characterise deformation mechanisms in the bedrock and overburden of the subsidence zone. In the discontinuous subsidence zone, the mechanisms controlling formation and behaviour of large cracks have been characterised from inclinometer and surface monitoring data. For example, the deformation record in inclinometer 33105, combined with nearby survey prisms and monitored cracks, tracks the upward transference of displacement to surficial materials from the underlying bedrock.

Inclinometer 33105 was installed when nearby cracks were hairline-scale. In late 2015, reverse shear displacement was recorded in bedrock over a $5.5 \mathrm{~m}$ interval at a depth of approximately $80 \mathrm{~m}$, indicating movement of a bedrock block towards the cave area. Within six months, a smaller reverse shear developed in the overlying till at approximately $58 \mathrm{~m}$ below ground surface, signalling progression of the bedrock-driven deformation upward into the overlying till and waste rock units. Immediately thereafter, the inclinometer closed off at a depth of approximately $56 \mathrm{~m}$. At the same time, a nearby survey prism recorded an increase in movement rate towards the subsidence crater, and nearby cracks developed vertical offsets and horst-graben features began to form. Figure 8 shows the development of one of the nearby cracks with time. This particular crack became discernible on the drone orthophoto in April 2016, and it coalesced with bedrock cracks that daylight in the Afton Pit wall.

Inclinometer data within the southern subsidence zone generally exhibits an overall tilting or spreading trend that is continuous across unit contacts, rather than showing discrete shear planes. This is interpreted to represent a zone of fractured, deforming ground spreading towards the crater in response to stress relief and loss of confinement. The monitoring data indicates that movements are originating below the bedrock-till and till-waste rock contacts. Additionally, no correlation is evident when the contours of subsidence are compared with the thickness of waste rock or glacial till deposits. 

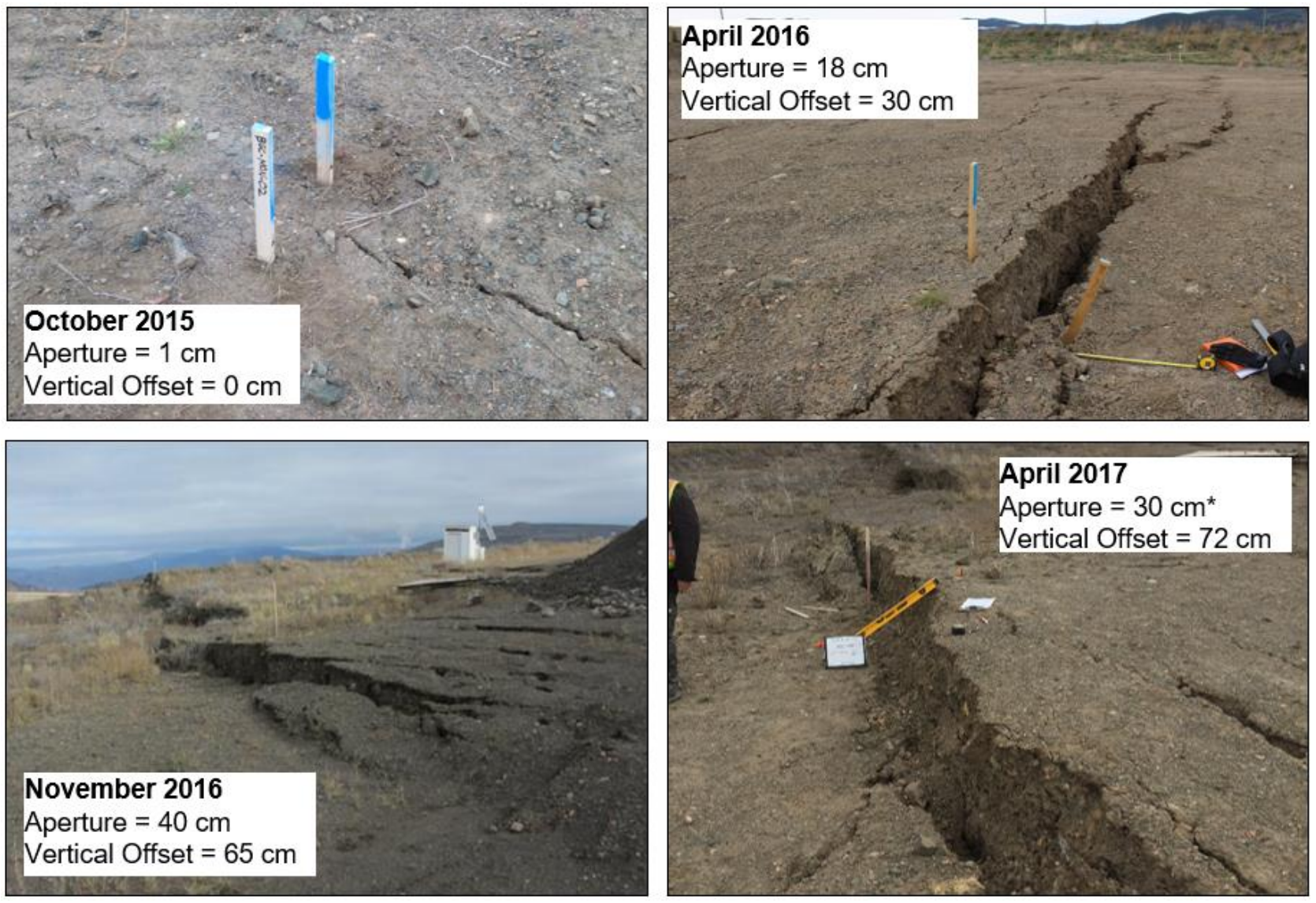

Figure 8 Photographs documenting growth of a surface crack in the waste rock overlying picrite in the discontinuous subsidence zone at New Afton (*apparent aperture reduction due to scarp HW sloughing)

\subsection{Conceptual model of subsidence behaviour}

A schematic illustrating the interpreted style of block cave-induced deformation at New Afton is shown in Figure 9. Geological structure data collected through borehole investigations and from historical records from the Afton Pit suggest a toppling along steep structures sub-parallel to the orebody as the most likely kinematic mode contributing to subsidence, which is consistent with this monitoring data. The mechanism of bedrock toppling from the sides of a cave is well-supported in literature (Brady \& Brown 2004); in the case of New Afton it is also consistent with deformation behaviour observed during the excavation of the Afton Pit (Reid \& Stewart 1986). The waste rock unit movements are interpreted to be occurring in response to both the underlying bedrock movements, which are variable across the site, and the release of confining stress caused by the deepening subsidence crater.

Subsidence in response to block cave mining draw is expected to continue, with variation in the location and magnitude of ground deformations dependant on the changing geometry of the active caving footprint and extraction rates. The style of movement will continue to be influenced by geological structure and rock mass strength (taking advantage of existing structure and zones of weaknesses). 


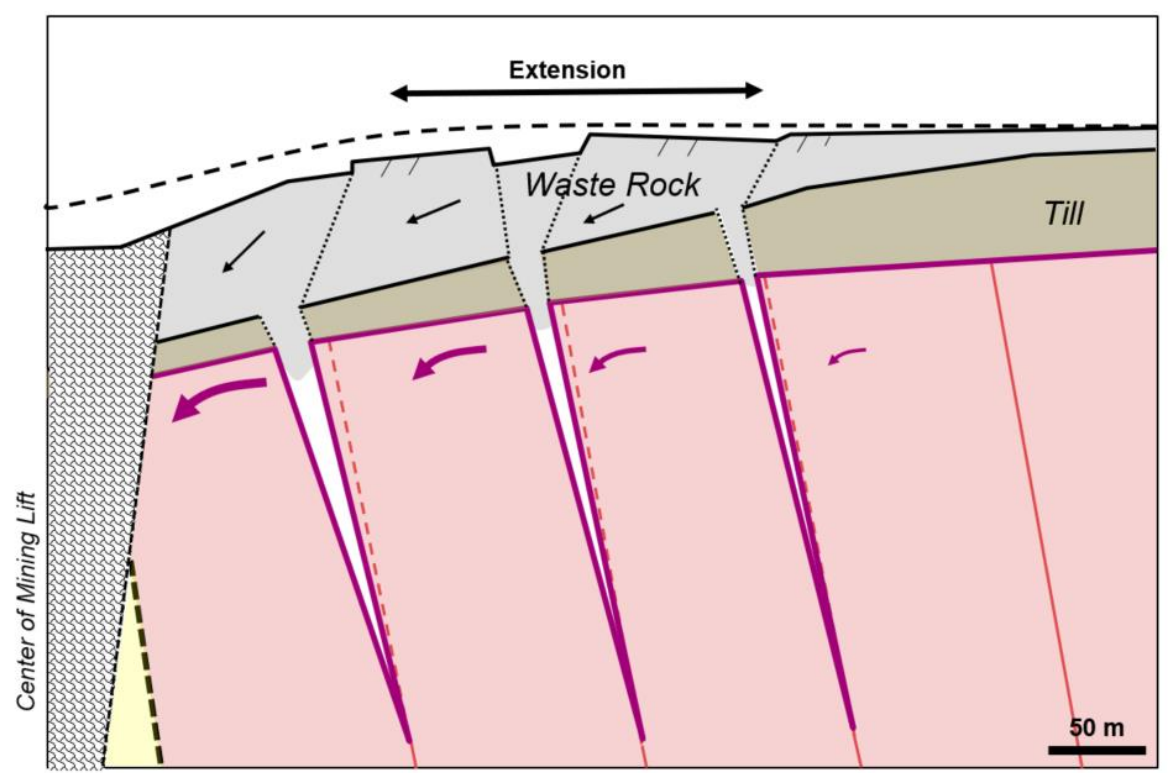

Figure 9 Schematic cross-section of subsidence zone deformation south of the New Afton block cave. Toppling bedrock overlain by thick till and waste rock extending in response to underlying bedrock movement

\section{Conclusion}

Important decisions regarding surface infrastructure planning and placement often need to made very early on during the project phase of a mine and are often based on very sparse information used in predictive models. Unexpected subsidence impacts on critical infrastructure from a block cave operation can obviously have enormous consequences for an organisation. Existing numerical modelling methods and computing performance have evolved noticeably over the past few years. However, a vast number of unknowns remain, and the global-scale (inherent to cave mining) at which these models are attempting to simulate rock mass behaviour is still a major challenge.

New Afton has seen its fair share of challenges with model calibration over the past few years, and efforts to maintain calibration and further our understanding of the rock mass response continue. Fundamental to our success has been the proactive measures taken in creating a superb and robust instrumentation network. The value of the data obtained from the instruments cannot be overstated. The close coupling of this data to both the continuous model inputs and its use in our ability to formulate sound mechanisms for rock mass behaviour has been invaluable.

Of all the subsidence learnings that were gained at New Afton, we firmly believe that unless you can understand the underlying rock mass mechanisms, associated responses and have a good understanding of your regional structure and lithology, you will constantly question the validity of your numerical model predictions.

\section{Acknowledgement}

A large number of people have been involved at various levels in this very successful collaborative effort between BGC Engineering, Knight Piésold and New Gold. The authors thank all project staff closely involved with the project, and the drilling contractors who persevered through challenging situations and conditions.

BGC Engineering makes special mention of Jennifer Brash and Chris McKane. From Knight Piésold, special mention goes to Louise Shannon and Dan Friedman. From New Gold, thanks go to Corey Kamp for his assistance with instrumentation installs and data interpretation. 
Finally, this project would not have been possible without the support from site and senior management within New Gold. Special mention from this group must go to Scott Davidson for his continued encouragement, support and assistance in the entire subsidence project.

\section{References}

Beck, DA \& Putzar, G 2011, 'Coupled flow-deformation simulation for mine scale analysis of cave initiation and propagation', in Q Qian \& Y Zhou (eds), Proceedings of the 12th International Congress on Rock Mechanics, CRC Press, Boca Raton.

Beck, DA, Sharrock, G \& Capes, G 2011, 'A coupled DFE-Newtonian Cellular Automata scheme for simulation of cave initiation, propagation and induced seismicity', Proceedings of the 45th US Rock Mechanics/Geomechanics Symposium, American Rock Mechanics Association, Alexandria.

Brady, BHG \& Brown, ET 2004, Rock Mechanics for Underground Mining, 3rd edn, Kluwer Academic Publishers, Norwell.

Clayton, MA, Dugie, M, LeRiche A, McKane, C, \& Davies, A 2018, 'Development of a monitoring network for surface subsidence at New Gold's New Afton block cave operation', in Y Potvin \& J Jakubec (eds), Proceedings of the Fourth International Symposium on Block and Sublevel Caving, Australian Centre for Geomechanics, Perth, pp. 717-732.

Flatten, A \& Beck, DA 2015, 'Applications of hydro-mechanically coupled 3D mine and reservoir scale, discontinuous, strain-softening dilatant models with damage', Proceedings of the 49th US Rock Mechanics/Geomechanics Symposium, American Rock Mechanics Association, Alexandria.

Gibson, W 2008, Appendix 1 (Subsidence Report), Numerical Assessment of the Surface Deformation at the Tailings Dam Location due to the Block Cave Operation, Ref. 507020, internal report, New Gold Inc., Vancouver.

Levkovitch, V, Reusch, F \& Beck, DA 2010, 'Application of a non-linear confinement sensitive constitutive model to mine scale simulations subject to varying levels of confining stress', in J Zhao, V Labiouse, JP Dudt \& J-F Mathier (eds), Proceedings of Eurock 2010: Rock Mechanics in Civil and Environmental Engineering, CRC Press, Boca Raton, pp. 161-164.

Lipske, J \& Wade, D 2014, Geological Model of the New Afton Copper and Gold Deposit, British Columbia, internal report, New Gold Inc., Vancouver.

Reid, G \& Stewart, D 1986, 'A large scale toppling failure at Afton', in RK Singhal (ed.), Proceedings of the International Symposium on Geotechnical Stability in Surface Mining, A.A. Balkema, Rotterdam, pp. 215-223.

Sainsbury, B, Pierce, ME \& Mas Ivars, D 2008, 'Analysis of caving behaviour using a synthetic rock mass - ubiquitous joint rock mass modelling technique', in Y Potvin, J Carter, A Dyskin \& R Jeffrey (eds), Proceedings of the 1st Southern Hemisphere International Rock Mechanics Symposium, vol. 1, Australian Centre for Geomechanics, Perth, pp. 343-252.

Thomas, M \& Stewart, C 2007, April 2007 Afton Project Feasibility Study (Underground Mining Study), AMC 305086, internal report, New Gold Inc., Vancouver. 